\title{
DEEP CONCEPTUAL MORAL DISAGREEMENTS : OVER WHAT DO WE DISAGREE AND WHY?
}

\section{Sutrop, Margit}

2020

Sutrop , M 2020 , ' DEEP CONCEPTUAL MORAL DISAGREEMENTS : OVER WHAT DO

WE DISAGREE AND WHY? ' , Trames , vol. 24 , no. 3 , pp. 295-314 . https://doi.org/10.3176/tr.2020.3.03

http://hdl.handle.net/10138/320444

https://doi.org/10.3176/tr.2020.3.03

unspecified

publishedVersion

Downloaded from Helda, University of Helsinki institutional repository.

This is an electronic reprint of the original article.

This reprint may differ from the original in pagination and typographic detail.

Please cite the original version. 


\title{
DEEP CONCEPTUAL MORAL DISAGREEMENTS: OVER WHAT DO WE DISAGREE AND WHY?
}

\author{
Margit Sutrop \\ University of Tartu and University of Helsinki
}

\begin{abstract}
We frequently find ourselves in intractable disagreements about the morality of abortion, euthanasia, restrictions to freedom, or eating meat for fun. An adequate reaction to a disagreement requires knowing which type of disagreements we are confronted with. The main aim of my paper is to explain the source of moral disagreements and clarify their nature. I will argue that some moral disagreements are deep conceptual disagreements that similarly to disagreements in logic or ontology, are not resolvable, as the resolution of the disagreement requires the disputants to adopt perspectives that are conceptually unavailable to them. I will suggest four possible sources of moral disagreements: incommensurable fundamental values, different concepts of the good life, different motivating reasons and different concepts of morality.
\end{abstract}

Keywords: moral disagreement, deep conceptual disagreement, belief-disagreement, actiondisagreement, value, value conflict, identities, concept of good life, incommensurable values, motivating reasons, moral conflict, moral dilemma, concept of morality

DOI: https//doi.org/10.3176/tr.2020.3.03

\section{Introduction}

In contrast to traditional societies, modern pluralist societies can no longer take agreements for granted. On a societal level, it almost seems as if dissent with regard to moral questions is quite normal, while moral consensus represents an exceptional phenomenon (MacIntyre 1984: 6, Gordijn 2001: 225-226). Because of the field work of social scientists and far greater opportunities for travel and communication, we are now more aware than ever before that different social and historical cultures regard different actions as permissible or impermissible. Indeed, there are also intractable moral disagreements in every society. Here are some examples: Should 
death penalty be permitted? Should abortion and euthanasia be allowed? Should homosexual couples be allowed to marry or adopt children? Should prostitution be legalized? Should surrogate motherhood be allowed? Is it morally acceptable to eat animals or should we all become vegans? Should consumption of alcohol be permitted in public places? Are people free to express their views or should hate speech be prohibited?

In all these cases of moral disagreements underlie divergent views as to what policies should be adopted. As these disagreements involve some values and the 'ought' or 'ought not' distinction, they therefore fall under a category of normative disagreements. The parties involved in normative disagreements not only disagree about the handling of the issue under dispute, but also about the correct justificatory reasons for their contrary claims.

Moral disagreements have both theoretical and practical implications. The lack of decisive arguments in support of one's position on these controversial issues may lead one to suspect that some moral issues have no objectively true answers; that moral principles are relative to a society (relativism) or even to an individual (subjectivism). Even under ideal conditions, when all parties arguing about moral questions are knowledgeable and rational, we cannot expect unanimity in judgements. This makes some ethicists ask whether ethical judgements are answerable to anything independent of them. One possible explanation is that there simply is no objective reality (moral facts) that can be captured by our moral judgements.

The argument from disagreement has motivated various antirealist views: Mackie's error theory (Mackie 1977); the expressivist tradition (Stevenson 1963, Hare 1963, Williams 1985, Blackburn 1998, 1999, Gibbard 2003) as well as forms of relativism (Harman 1975, 2000, Dreier 2009). Realists in ethics (McNaughton 1988, Brink 1989, McGrath 2007, Shafer-Landau 2005) have replied in one or more ways: (1) we have no access to existing moral truths (2) existing disagreement is merely verbal or apparent; (3) some disagreements are due to objective value incommensurability; (4) local irresolvable disagreements exist, but entail no metaphysical consequences for ethics as a whole.

On the other hand, persistent moral disagreements raise the practical question as to how to manage our coexistence with those whose opinions we do not share (Archard 2012, Ceva 2016, Gowans 2000, Hanrick and Druckman 2017, Mason 2018, Wong 1992, 1995). The consequences of moral, political, and religious disagreements can be very serious, as conflicts can overflow state boundaries and even lead to war. It has been suggested that consensus resolves disagreement in an epistemic sense, while compromise resolves disagreement in the practical sense as it prevents the potentially negative consequences from occurring (Spang 2017).

What we should aim toward in moral debates is what Marino calls "case consistency": judging similar cases similarly (Marino 2015). The same applies to our judgements about overall obligations. People may fail to judge cases consistently because they may be distorted by emotions, self-interest or other biases. Here improved reasoning and focusing on case consistency can help. But in relation to moral matters we cannot expect agreement in all cases as people direct and prioritize 
values differently and there can be multiple internally coherent moral systems that do not agree with one another (Marino 2017: 482). I think that even if this does not bring us closer to consensus, it is important to be aware of why we cannot resolve disagreements even if each party is reasoning well.

The main aim of my paper is to explain the source of moral disagreements and clarify their nature. An adequate reaction to a disagreement requires knowing which type of disagreement we are confronted with. I claim that several moral disagreements are deep conceptual disagreements for the resolution of the disagreement requires the disputants to adopt perspectives that are conceptually unavailable to them. Although deep disagreements are not subject to rational resolution, there is still a rational way to deal with them. We can attempt to bring the framework propositions and concepts that lie at the bottom of deep disagreements to the surface and discuss them directly (Fogelin 1985: 5). Even if we cannot resolve a disagreement, it is important to understand why we disagree and why we cannot come to an agreement through the use of argument. Consensus or compromise can evolve from considering the other possible points of view.

My paper consists of three parts. In the first part I will analyse what is the specificity of moral disagreements and over what do we disagree. In the second part I will deal with different conceptions of value and show what the empirical studies show about relativity or universality of values. In the third part, I will suggest that there are at least four possible sources of moral disagreements: different concepts of good life, related to our identities, incommensurable fundamental values, different motivating reasons, and different concepts of morality.

\section{What is specific about moral disagreements?}

Noticing that one is in disagreement with other people over some fact in a matter may lead one to think that his/her belief is false. When does this happen? Bryan Frances and Jonathan Matheson (2018) explain the epistemological implications of disagreement as follows:

If learning that a large number and percentage of your epistemic peers or superiors disagree with you should probably make you lower your confidence in your belief, then learning that those same individuals agree with you should probably make you raise your confidence in your belief provided they have greater confidence in it than you did before you found out about their agreement.

In order to judge how likely one is to be correct with respect to a given proposition, one has to judge one's epistemic position. The main disagreement factors, which help to determine one's epistemic position, are the following: data, evidence brought to bear on answering the question, cognitive ability and other intellectual virtues possessed while answering the question, relevant background knowledge, relevant biases, attentiveness and time devoted to answering the question (Frances 2014: 32). 
It is due to these disagreement factors that reasonable people may have reasonable but contrary beliefs. One's epistemic position describes how likely it is that one's judgement of a certain belief is correct. Depending on whether one believes that the persons who disagree with him/her over a certain belief are one's peers, superiors or inferiors, one either tends to stick with his/her belief or not. ${ }^{1}$

However, all this is not very helpful in case of moral disagreements. It has been pointed out by Frances and Matheson (2018) that in many real-world cases of disagreement it is not easy to judge which party is better positioned to answer the question at hand. The question of whether to seek experts' advice to solve peer disagreement about moral matters has led some philosophers to moral skepticism, because moral experts are impossible to identify (McGrath 2007, Decker and Groll 2013).

Although there may be moral disagreements that can be resolved when factual disagreement is removed or errors in reasoning have been detected, quite often moral conflicts persist despite agreement over empirical facts. In these cases, the commonsense recipe seems unhelpful: taking more time for discussion, checking that no mistakes have been made in the process of argumentation, and making sure that the facts on which views are based are accurate. Both in philosophy and in everyday deliberative democracy, it has been recognized over and over again that such interventions do not help the opposing sides closer to agreement. Disagreements that cannot be resolved through the use of argument and should be addressed by nonrational persuasion have been called 'deep disagreements' (Fogelin 1985, Adams 2005, Duran 2016). These disagreements are deep since the competing positions seem to be incommensurable; they cannot be compared because they do not rely on the same rule-based way of making and legitimizing judgements.

That some disagreements in ethics are deep disagreements was first indicated by Robert J. Fogelin (1985: 5-6). He showed that although there might be a good deal of agreement about many facts related to abortion, there is no common ground, and in the background of the debate there are some contradictory framework propositions about definitions of life which make it impossible to reach agreement. The disagreement is not over some isolated propositions such as "The fetus is a person", but instead over "a whole system of mutually supporting propositions (and paradigms, models, styles of acting and thinking)" that in his wording constitute a form of life (Fogelin 1985: 6). Fogelin's central thesis is that argumentative discourse necessarily occurs against a background of broadly shared beliefs, preferences and procedures for resolving disagreements, as well as shared commitments to producing compelling grounds. If this shared background is absent, and argumentative context becomes less normal, argument becomes impossible. Deep disagreements cannot be resolved through the use of argument as they are generated by conflicts between underlying principles or what Wittgenstein was inclined to call 'rules' or what Putnam called 'framework propositions' (Fogelin 1985: 5).

${ }^{1}$ An empirical study (Ahola 2017) which investigated accociations of human values with the readiness to question experts' views showed that the reasons for disagreeing with experts are related to individual factors, situational factors, social risks and views about experts. 
Chris Ranalli (2018) has pointed out that recent discussion has tended to focus too much on the epistemic issues, such as whether deep disagreements are rationally resolvable, or whether deep disagreement supports epistemic relativism, instead of answering the metaphysical question of what deep disagreement consists of. The fact that some moral disagreements are not rationally resolvable raises both metaphysical and epistemological questions, whereas the answer to the metaphysical question may influence the way we answer the epistemological question. For example, if, given the nature of what one disagrees over in moral disagreements, it turns out that we are dealing with non-doxastic disagreements, this may also explain why they are not rationally resolvable. Or, if some moral disagreements turn out to be deep disagreements, this can also have important ramifications for the epistemological question.

\subsection{Over what do we disagree?}

Let us first try to find out what is the object of disagreement. Epistemologists (Frances and Matheson 2018) distinguish between 1) disagreements over what to believe (disagreement over the truth of a claim) and 2) disagreements over what to do (disagreement over an action). The first of these has been referred to as beliefdisagreement and the second, as action-disagreement. When it comes to beliefdisagreements, one has three possibilities: to believe it, disbelieve it, or to suspend judgement. With action-disagreements, one also has three options: to do X, not to do $\mathrm{X}$, or to prevent doing $\mathrm{X}$, while in cases when one is not able to decide whether to do $\mathrm{X}$ or not to do $\mathrm{X}$, it amounts to the same thing as not doing $\mathrm{X}$.

Bryan Frances has argued that although we can distinguish between beliefdisagreements and action-disagreements, for the sake of simplicity and uniformity action-disagreements can also be constructed as disagreements over what to believe. In this case the disagreement will be over the truth of the claim "One should do X" (Frances 2014: 76). Frances points out that it is important to remember that actiondisagreements are not identical with belief-disagreements, since besides belief the former also involve a choice about what one will in fact do, or what one actually ought to do. However, all things considered, Frances does not think that translating action-disagreements into belief-disagreements gets us in trouble. I believe that here Frances has overlooked the implications of the translation of action-disagreements into belief-disagreements, namely that action-disagreements involve one additional element: in order to do something, one needs to have a motivating reason to do so.

What does it mean for someone to have a motivating reason? There is a dispute between Humeans and anti-Humeans on what it is to have a motivating reason, whether we are just believers, desirers or, rather, besirers. To my mind Michael Smith (1994) has convincingly shown why Humeans are right that only an agent's desires may constitute her motivating reasons. According to the dispositional theory of desire developed by Michael Smith (1994), desire means an agent's propensity to take a given course of action. In order to show how motivating reasons are related to having goals and desires, Michael Smith (1994: 116) introduces following steps: 
1. Having a motivating reason is, inter alia, having a goal.

2. Having a goal is being in a state with which the world must fit.

3. Being in a state with which the world must fit is desiring.

It follows that having a motivating reason is, inter alia, desiring.

Timo Airaksinen (2016: 33) has shown how desires are connected with the agent's values: the agent feels the pull toward the object because $\mathrm{s} / \mathrm{h}$ e registers his/her values and formulates the corresponding desire, which is a motivating factor for action. The values tell what the agent likes. But they also tell what the agent wants, and therefore they are a source of his/her experienced desirability (Airaksinen 2016: 35).

I hope that it has become clear why it is important to retain the distinction between belief-disagreements and action-disagreements. The answer is that actiondisagreements may be either disagreements on beliefs (when we disagree on the truth of the claim "One should do X") or disagreements on desires (when we disagree, for example, on whether one finds it important to promote or honour some value). Later on, in part 4.3 of this article, I will show how different approaches to motivating reasons can lead to deep moral disagreements.

\subsection{Moral conflicts are more like desires than like beliefs}

Already more than half a century ago Bernard Williams pointed out in his article "Ethical consistency" (1965/1973a) that moral conflicts resemble conflicts of desires more than conflicts of beliefs. He foregrounds two aspects which should demonstrate this. First, our reactions upon noticing a conflict vary: if I find out that my beliefs are in conflict, this weakens either one or other of the beliefs, but the same does not happen with desires. The clash between desires arises from some contingent matter of fact which makes it impossible to satisfy both desires. In a situation in which one has to choose between two moral 'oughts', knowing that both apply but one cannot follow them both, there is a feeling of being ripped apart. One does not have this feeling in a situation where one has two different beliefs, except in a situation when one unconditionally wants to believe something. Secondly, when I finally make a decision about which of the two 'oughts' to follow, the result is a feeling of regret, similarly to when I decide to satisfy one desire and not another. Despite feeling that I did the best I could in the situation, I will still feel regret as I may continue to think retrospectively that these were both things that I ought to do (Williams 1965/1973a: 172).

Williams makes the critical point that a cognitivist construction of a conflict of obligations does not take the phenomenon of regret into account. This is because cognitivists treat moral conflicts as conflicts of belief, in which there is only one right choice. The whole endeavour is directed toward freeing oneself of the mistake whereby two contradictory ought-statements have been constructed. Often this is attributed to the affective element which one should get rid of.

That this is so can clearly be seen in realism proponent Russ Shafer-Landau's argument that although realists claim that in a case of moral disagreement, one party makes a cognitive error, this would be over-intellectualisation. He confirms that "moral error is first and foremost a matter of conative misalignment" (Shafer- 
Landau 2005: 217). A moral error may indeed consist of acquiring a false belief, but there are also many other (affective) elements which lead to application of the wrong standards, such as emotions, moods, upbringing, cultural context, desires and lusts, dreams and fears, all of which play a role in a person's moral beliefs. Shafer-Landau explains that moral error that involves attachment to false moral standards "often signals an affective misalignment as well" (Shafer-Landau 2005: 218).

It is typical of cognitivists that desires and emotions are represented as annoying intruders that make us diverge from a rational understanding of the 'right' moral standards. In the cognitivist view, the affective element that accompanies a moral decision should be eliminated, because it interferes with following objective standards. In addition to Bernard Williams (1973b), such an approach has been criticised by Martha Nussbaum $(1986,2001)$ and others, who have shown that emotions play an important role in morality. Also, several social scientists (Haidt 2012, Bartels 2008) have stated that in moral and political questions, one has to do with non-rational disagreements, which are based on emotions and intuitions, and which refuse to submit to rational arguments. I think that these thinkers are right in that emotions do play an important role in moral and political disagreements. Emotions and desires are not only factors that have to be eliminated in order to reach a correct moral judgement; rather, they are essential elements of moral decisionmaking and play a major role in moral conflicts. ${ }^{2}$

\subsection{Moral conflicts, moral dilemmas and moral disagreements}

Let us now clarify the relationship of moral conflicts, moral dilemmas, and moral disagreements. Moral conflicts are incidents in which there are two normative requirements as options - each entailing an action realizing a moral value and one has to find out in moral deliberation, for instance, in all things considered judgement, which requirement overrides the other and then act on the basis of this requirement. In a moral dilemma, none of the requirements overrides the other, even though both are binding. Moral dilemma is "a situation in which an agent $S$ morally ought to do $A$ and morally ought to do $B$, but cannot do both, either because $B$ is just not-doing- $A$ or because some contingent feature of the world prevents doing both" (Gowans 1987: $3)$. Williams (1981) indicates that the difference between a moral conflict and moral dilemma is that in the first case one obligation can be genuinely outweighed, so that the disadvantaged party will not have justified complaint about what I chose to do, whereas in the case of moral dilemma there are conflicting moral requirements and neither of them succeeds in outweighing the other. Thus, this situation is 'tragic' as whatever the agent does there will be a moral residue (Williams 1981: 74).

Williams explains that by 'moral conflict' he means "cases where there is a conflict between two moral judgements that a man is disposed to make relevant to deciding

2 In a previous article, "What role do emotions play in moral disagreements?" (Sutrop 2016) I have shown that since emotions lead one to see things in a particular way, in case of moral disagreements it is important to put oneself imaginatively in the other person's shoes to understand where the emotion comes from. In order to resolve a disagreement, one should aim to change other person's emotions related to the debated issue or to revise one's own emotional repertoire. 
what to do" $(1965 / 1973 a)$. He shows that moral conflicts can take two forms: in the first form I ought to do both $a$ and $b$, but I cannot do both; in the second form I ought to do $c$ in respect of some of its features but in respect of its other features I should not do $c$. In the case of a moral dilemma both 'oughts' apply but they cannot be acted upon. This shows that the two 'oughts' are incompatible. This is what makes moral dilemmas irresolvable (Williams 1965/1973a: 171).

Although most moral dilemmas involve just one person, sometimes dilemmas are faced by a group of people who have to decide what to do in case of conflicting obligations. For instance, in the case of Covid-19 pandemic a situation developed in several countries with insufficient intensive care beds for all who needed them, and doctors were put in the situation where they were not able to fulfil both the duty of beneficence and the duty of non-maleficence. In the circumstance where the lifesaving treatment of one patient had to be stopped in order to give respiratory support to another with a more positive medical prognosis, the hospital and doctors working in intensive care faced a moral dilemma: they had to fulfil the duty to help and at the same time fulfil the duty not to harm. Whatever the doctors did, they had a feeling that it was wrong as they were not able to do everything that should have been done for their patients. Such situation is tragic in its essence and puts great psychological pressure on health care providers (Sutrop and Simm 2020: 255).

According to Bernard Williams moral conflicts can be one-party or two-party conflicts (1981: 72). One-party conflict refers to the conflict of obligations in one person. Moral disagreements are two-party moral conflicts in which the parties have conflicting judgements about determinately specified actions. The parties involved in the dispute disagree over what to do in the case of conflicting moral obligations. Sometimes the parties in these disputes experience or have experienced internal (oneperson) moral conflict before they came to the decision which obligation outweighs the other.

The debate on moral conflicts is as old as history of philosophy. Moral conflicts occur in theories that involve more than one principle. Pluralists believe that moral conflicts are inevitable, and that there are many alternative ways of resolving such conflicts as there is no overriding value (Kekes 1993: 53ff). Moral pluralism opposes the monistic view "that all moral conflicts can be resolved on the basis of the overriding value whose authority all reasonable people should recognize" (Kekes 1993: 53). Although nobody denies that there are apparent moral conflicts, monist philosophical theories, among them utilitarians and Kantians assume that they are not genuine and can be resolved with the help of the ultimate principle as the source of moral obligation. Value pluralists believe that there are genuine moral conflicts as there is incommensurability of moral values. Incommensurability may mean different things but the core claim is that "there is no currency in terms of which each conflict of values can be resolved; and that there is no value, which can be appealed to, independent of the conflicting values; and no conflict can be rationally resolved (Williams 1981: 77). Moral pluralism differs also from the relativist view that all things have value only with respect to a particular cultural context or situation. Relativists deny that there is a uniquely correct answer to resolving moral 
conflicts, they "hold that social convention plays an ineliminable role in selecting which values a group's morality emphasizes the most and in dealing with conflicts between important values" (Wong 2006: 374).

Although in case of one-party moral conflicts it is assumed that the rational agent will be able to solve or at least reduce conflict in his/her personal set of values to a minimum, in Williams's view this is unreasonable, since conflicts of values are "expressions of a complex inheritance of values, from different social sources, and what we experience in ourselves as a conflict is something which could have been, and perhaps was, expressed as a conflict between two societies, or between two historical states of one society" (Williams 1981: 72-3). Interpersonal conflicts in society are disagreements which in Williams's view are similar to one-person conflicts, expressing clashes of values and value systems of different origin. He points out that it is often wrongly assumed that each party has their own harmonious set of value-beliefs, and that they will be able to resolve the conflict rationally.

A similar view has been expressed by Alasdair MacIntyre (1984) who argues that disagreements on a variety of ethical issues are the result of the fact that we have inherited fragments of heterogenous moral theories that we cannot put in harmony as these theories have their roots in different social contexts.

\section{What is universal and what is culturally specific about values?}

\subsection{What are values?}

Although value is a central concept of ethics and various social sciences, it is rarely defined. Sometimes the word 'value' is used narrowly as a synonym for the words 'good' and 'valuable', and at other times as a reference for the whole scale of evaluatory terms, at one end of which are positive, at the other negative values. In order to avoid verbal disagreement where people are talking past each other, it would be important to clarify what we mean by value.

Let us start with etymology. The word 'value' comes from the Latin word valere, meaning to be worthy (Bond 2001: 1745). Thus, in its most general meaning a value is something worthy, which is worth having, getting or doing, or that possesses some property or properties that make it so. Values are action-guiding, as we take them into account when making decisions and when planning activities. If a value is something that guarantees individual well-being and flourishing, there is an internal relation between the concept of value and the concept of good. However, this relational account of values is challenged if there is such a thing as intrinsic value (Bond 2001: 1745). While intrinsic values (e.g. beauty, the good will, happiness) are things that have value in their own right, instrumental values are things that contribute to human flourishing, survival, growth, or the well-being of human beings, and mixed values are simultaneously good in themselves as well as being vehicles for attaining other things considered to be good (e.g. health or knowledge).

Philosophers also debate about whether values are subjective or objective. They ask whether certain things are valuable because we desire them, or whether we 
desire them because they are valuable. And last but not least, there are arguments as to whether every culture has its own values or own rankings of values, or whether there are at least some values that apply always and everywhere.

Francesco Orsi (2015: 7-8) has shown that the word 'value' may refer to three different things: (1) the object or state of affairs that has value, (ii) the features that make an object or state of affairs valuable, and (iii) the fact that an object or state of affairs has value (is good, bad, etc.).

Traditional axiology deals with the questions concerning what things are good, how good they are, and how their goodness is related to one another (Schroeder 2016). Contemporary philosophers have mostly been interested in the nature of value and its relation to other moral categories, such as right, reason, rational, and ought, and whether these deontic categories are posterior or prior to the evaluative categories.

In his book Value theory (2015), Francesco Orsi explores the nature of evaluative concepts used in everyday speech and in contemporary philosophical discourse with special attention to different forms of fitting attitude theory. The basic idea behind the fitting attitude account is that good is closely linked to 'desirable'. Orsi shows that evaluative and normative dimensions of value are interlinked. As normativity is one of the fundamental properties of value, for something to be good means nothing more than that there are reasons to respond favourably to it (Orsi 2015: 11). For instance, to consider a certain conduct to be morally good implies that there is some reason to admire it. A general rule is that a positive value is to be responded to with a positive attitude while a negative value entails a negative attitude.

There are several types of values: biological-physical values (life, health, environment), socio-political values (freedom, justice, tolerance, cultural diversity), moral values (honesty, caring, goodness, human dignity), and aesthetic values (beauty, symmetry). For discussing moral matters, it is useful to distinguish between moral and non-moral values; moral values secure the well-being of other people, and non-moral values are beneficial to the agent.

Because there is such a multiplicity of values, the question arises of interrelationships among them, i.e. whether values can be (in)comparable and (in) commensurable. Value (in)commensurability entails two further issues: the way one should relate moral values to each other and what one should do in cases of conflict (Viganò and Vallauri 2020: 87). For monists, a single scale enables the agent to compare conflicting oughts and reduce different values to one ultimate value. For example, most utilitarian and Kantian theories are monist and identify, respectively, either happiness/utility or respect as the ultimate value. According to pluralists such an ultimate value does not exist. They argue that many values are characterized by incommensurability or incomparability. For Joseph Raz (1986: 329) the idea of incommensurability entails the idea of incomparability: when two things are incommensurable, they cannot be meaningfully compared. This view was questioned by James Griffin (1986: 77) arguing that although two things cannot be measured by any common scale of value, we can still compare and rank them. Ruth Chang claims that these terms are distinct: the term 'incommensurable' should be reserved for items that cannot be precisely measured by some common scale of units 
of value and the term 'incomparable' for items that cannot be compared because no positive value relation holds between them (Chang 1997: 2). Positive value relation is the judgement that between two options one is either better than the other or they have equal value (Chang 1997: 4).

T. K. Seung and Daniel Bonevac (1992) have made a suggestion that we should distinguish between 'incommensurate ranking' where comparing of values is done in reference to some particular value-measure, and 'indeterminate ranking' where one considers all things and makes the on-balance comparison of two values. They argue that "instead of one right solution, indeterminate ranking offers a range of right solutions" (Seung and Bonevac 1992: 802). Thus, some pluralists argue that it is possible to arrange values according to their relative importance, but the bases of prioritizing among them, arranging them in a hierarchy are also multiple (the concept of the plurality of measures). It is believed that if some things really are incomparable and incommensurable, then value pluralism could explain why (Schroeder 2016). However, as practical life requires being able to make choices and solve value conflicts, this makes monism attractive. It has been argued that pluralism typically appeals to those who want to explain why moral conflicts arise, whereas monism appeals to those who seek to organise the precepts of morality without moral remainders (Brunning 2019).

\subsection{Value priorities of different cultures}

It is noteworthy that philosophers have not been much interested in how people in real life make value choices and what they value in different cultures. Since 1981 a worldwide network of social scientists has conducted representative national surveys of people's values and beliefs in almost 100 countries as part of the World Values Survey (Inglehart et al. 2014). The World Values Survey measures support for democracy and gender equality, tolerance of foreigners and ethnic minorities, the role of religion, attitudes toward the environment, work, family, politics, national identity, diversity, culture, and subjective well-being. On the basis of the World Values Survey data, political scientists Ronald Inglehart and Christian Welzel (2005) developed a cultural map of the world which shows how closely linked cultural values vary between societies in two major dimensions: traditional versus secularrational values on the vertical y-axis and survival versus self-expression values on the horizontal x-axis. Moving upward on this map reflects a shift from traditional to secular-rational values and moving toward the right reflects a shift from survival to self-expression values. Traditional values emphasize the importance of religiosity, national pride, family values, respect for authority and obedience. Secular-rational values stress autonomy. Support of traditional values leads one to reject divorce, abortion, euthanasia and suicide, while those who support secular-rational values are more likely to accept them. Survival values involve a priority of security over liberty, non-acceptance of homosexuality, distrust in outsiders and abstinence from political action. Self-expression values involve prioritization of individual freedom and activist political orientation (environmental protection, speaking out for gender equality, sexual minorities), and toleration of foreigners. 
The Inglehart-Welzel cultural map helps us to understand why we have so many moral disagreements over a variety of issues. The data show that much of the variation in human values between societies boils down to these broad dimensions: traditional vs secular-rational values and survival vs self-expression values (Inglehart and Welzel 2005). As basic living conditions differ much more between than within societies, as do the experiences of existential security and individual agency, the societal differences are greater than the individual ones. Being aware of this fact, we could be better prepared to deal with value conflicts between societies. If our different views are embedded in deeply rooted value systems which have been influenced by socio-economic conditions, the level of modernization, or our relationship to religion, convergence of values may only take place as a result of long-term socio-economic and cultural changes.

At the same time it is clear that cultures are not homogeneous, and there are also large individual differences within societies along such cleavage lines as gender, generation, ethnicity, religious denomination, education, income, etc. People's priorities shift from traditional to secular-rational values as their sense of existential security increases or backwards from secular-rational values to traditional values as the feeling of security decreases. The move from survival values towards selfexpression values requires the increase of the sense of individual agency. This has a direct influence on how we think of the issues of abortion, euthanasia, gay and lesbian partnerships or animal rights. As we know, these are the issues that most often lead to moral disagreements.

The empirical studies on values also show that our values are of various derivations and can form very different sets. However, even if our values are deeply embedded in our socio-economic and cultural settings as well as dependent on our individual life situations, there is always some room for reflection, individual judgement and moral deliberation which can influence our views on moral issues. People's mind can be changed by values education (Sutrop 2015), through the means like art, and literature, or personal activism - by standing as a representative of the values one endorses (Marino 2017).

\section{What are the possible sources of moral disagreements?}

Let us now come back to the question over what we may disagree when we talk about moral matters. It has been pointed out by Frederico Zuolo and Giulia Bistagnino (2018: 597) that in deep normative disagreements the parties involved may disagree either about the substantive content of the issue under dispute (firstlevel disagreement), or about the correct justificatory reasons for their contrary claims (second-level disagreements). Using the example of the death penalty they show that it is possible to have a second-order disagreement even when the parties agree on the first level. In this case the disputants may agree on the first level that the death penalty is morally wrong but provide different justifications for this judgement (Zuolo and Bistagnino 2018: 598). In the following, I will show what can cause our disagreements both on the first and second level. 


\subsection{Disagreements caused by our different identities and concepts of the good life}

Firstly, we may disagree about our judgement of the subject matter as we have different concepts of the good life. We also differ regarding what kind of persons we want to be. This general claim can be divided into several subquestions. (1) Which character traits are important to us? (2) Which moral principles do we consider important? (3) Which roles we identify with (professional roles, roles in family life, other personal relationships or society)? (4) To whom do we want to be loyal - to which persons, institutions, or to oneself? Also, we have differences in the following aspects: (5) What we believe in (i.e. religious beliefs), and (6) What is important to us (how we relate to power, achievement, tradition, hedonism, conformity, security); (7) What aims we have in our lives.

Already Isaiah Berlin argued that moral debates are not like debates over taste in the form of "I prefer coffee, you prefer champagne", which epistemologists today call 'faultless disagreements' ${ }^{3}$ rather, they are debates over deeper identities (Berlin 1947/2013: 11). Moral disagreements are not about who is right or wrong, but about different identities and incompatible human goals. In his famous essay "Two concepts of liberty" (1958/2002) Isaiah Berlin argued that the freedom to choose between ultimate values makes us human. Value conflicts are frequent because we want to realize incompatible human goals. Politics and political theory have been invented because of men's disagreements about the ends of life. In "The pursuit of the ideal" (1947/2013) Berlin writes:

What is clear is that values can clash - that is why civilizations are incompatible. They can be incompatible between cultures, groups within the same culture, or between you and me. You believe in always telling the truth, no matter what: I do not, because I believe that it can sometimes be too painful and too destructive to do. We can discuss each other's point of view, we can try to reach common ground, but in the end what you pursue may not be reconcilable with the ends to which I find that I have dedicated my life (Berlin 1947/2013: 12).

Values can also come into conflict within a civilisation and give rise to intense arguments that do not necessarily resolve by deciding that one value is unconditionally wrong and the other right. For one person, justice may be the only value while for another, compassion and caring may be just as important, while not setting justice aside. Both liberty and equality are important values, "but total liberty for wolves is death to the lambs, total liberty of the powerful, the gifted, is not compatible with the rights to a decent existence of the weak and the less gifted" (Berlin 1947/2013: 12-13).

Axiological dissent is rooted in our very identity, according to Berlin: "These collisions of values are of the essence of what they are and what we are" (1947/2013: 13). He strongly insists that one should not look for one ultimate solution. If someone were to promise that it is possible to overcome these contradictions and that in some

3 A disagreement is 'faultless' when no party in a dispute needs to be mistaken. 
ideal world it is possible to harmonise all good things, then this in itself is forcing one's values on someone else, declaring them to be the only ones that are right. Incidentally, Berlin says that achievement of such complete harmony of values is not only unattainable but conceptually incoherent. This is how he explains it: "Some among the Great Goods cannot live together. That is a conceptual truth. We are doomed to choose, and every choice may entail an irreparable loss" (Berlin 1947/2013: 114). If Berlin is right about conflicting identities and the clash of fundamental values, then our moral disagreements are not apparent but deep disagreements.

\subsection{Disagreements caused by incommensurable fundamental values}

That our concepts of the good life and the good person are related to our fundamental values, has been suggested also by Thomas Nagel (1979) who distinguished between five fundamental types of value that give rise to a basic conflict. These types are (1) specific obligations to other people or institutions; (2) constraints on action deriving from general rights that everyone has; (3) considering and taking into account all aspects of benefit and harm to all people or all sentient beings (utility); (4) the intrinsic value of certain achievements or creations; (5) commitment to one's own projects or undertakings (Nagel 1979: 130).

Nagel says that these values enter our decisions on a daily basis, and we see constant conflicts among them and within them. Although attempts have been made to resolve such conflicts by arranging values in a particular order or subsuming some points of view to others, in Nagel's opinion this cannot succeed because values have fundamentally different kind of sources, and therefore we are confronted with incommensurable claims. Conflicts arise because the sources of value commitments are deeply different and they represent different points of view: individual, relational, impersonal, or ideal (Nagel 1979: 134). And all these ways of seeing the world - from the point of view of one's relations to others, across a lifetime, of everyone at once and from a detached viewpoint - are equally human characteristics. Moral conflicts are created by a disparity between the fragmentation of value and the singleness of decision.

These values may collide within a single type, as suggested by Nagel, or among different types, and there is no single overarching value to which different values can be reduced. In all five of Nagel's types there is the question of how important one or another kind of responsibility is to one or another person. The preference may also differ with the situation. In order to make a decision about what to do we have to find a balance between conflicting values. But this act of balancing has its basis in our conception of good life and depends on which kind of person we want to be. Also, I think that Nagel has put his finger on something really important when distinguishing between different types of values, he correlates them with different kinds of motivating reasons for moral action which may easily become a source of moral conflicts. 


\subsection{Disagreement over motivating reasons}

Thirdly, moral theories differ on which motivating reasons they provide for moral actions. Philip Pettit (1989) has drawn our attention to the fact that consequentialists and deontologists may share a theory of the good but they differ in the theory of the right, the theory of what makes us choose between different options (Pettit 1989: 117). That consequentialists and deontologists give different reasons for action has first been demonstrated by Stanley Benn in A theory of freedom (1988). Benn distinguished between person-centred and value-centred reasons (1988: 6-11). Person-centred reasons involve commitment to certain principles in our dealings with other people, quite irrespective of the outcomes of our conforming to these principles. Examples of person-centred reasons may be respect for freedom, justice, equal regard, or fidelity to truth. Value-centred reasons involve considerations of how to promote certain values or certain valuable properties. This will mean aiming to maximize certain goods such as personal freedoms or equal opportunities.

Philip Pettit (1989) developed this distinction further with the focus on value. Pettit argues that deontological and teleological ethical theories differ in their response to values: whereas deontologists tell us to honour a value, teleologists suggest that we promote a value. For example, promoting a value such as honesty means to aim to bring along a certain consequence, to increase truthfulness in the world, by encouraging as many people as possible to be honest. Honouring honesty means striving to be as honest as possible toward oneself, to respect the principle of honesty in one's own life and to refrain from lying. Promoting a value focuses not so much on the agent as on maximizing the value itself. Thus, in honouring a value, the agent acts on the basis of an agent-relative reason, while in promoting a value, the agent acts on an agent-neutral reason.

Although both the consequentialist and the deontologist may respond to the value of honesty by exemplifying it in their life and actions, her/his reasons for doing so are different. Such different reasons for action may sometimes lead to moral disagreements about what one ought to do. While honouring a value is also a way of promoting it, devoting oneself to fostering a value may mean focusing only on preventing more lies being told without thereby promoting truthfulness (one may be allowed to lie in order to reduce lies in the world). In addition, it may involve promoting truthfulness in one's own life, that is, a disposition not to lie.

Another example for demonstrating the contrast between the agent-relative (honouring a value) and agent-neutral (promoting a value) injunctions would be the example of killing. The question that may divide consequentialists from deontologists, is their attitudes to the question of whether it is permissible to kill in order to save more lives. "The agent-relative (AR) injunction requires that you not kill; the agent-neutral (AN) rule requires that you kill if you can thereby decrease the net amount of killing" (McNaughton and Rawling 1992: 836). 


\subsection{Disagreement over what makes some action or character trait morally good or bad}

Fourthly, moral disagreements may be caused by our different conceptions of morality. Whereas deontological ethicists construe morality in terms of duties and conflicts, and teleological ethicists focus on consequences, virtue ethicists construe morality in terms of virtues, ideals and ways of life. Michael Stocker has shown that what matters for Aristotelian virtue ethics is not an act-evaluation which is action-guiding but such an act-evaluation that also involves agent evaluation and the evaluation of moral emotions proper to each of the conflicting act-evaluations (Stocker 1990: 117). From this we can conclude that the moral theories disagree on whether morality is a matter of what I should do or a matter of what kind of person I should be and what kind of emotions I should feel.

Thus, some moral disagreements have their origin in the fact that there are different views on what makes an act morally good. Paul Walker and Terence Lovat (2018) have pointed out that historically there have been a variety of different positions on what makes an action or a character trait morally good, permissible, or obligatory. They remind us that a variety of suggestions have been made:

From a historical perspective, in the classical epoch, ethical appeal was made to the polis or to gods. In the medieval era, it was made to God. In the modern era ethical appeal in Western settings looks towards the rational framework of deontology, teleology or virtue ethics, among others. Under these frameworks, the moral permissibility of an act or decision depends either on the intrinsic nature of the act (i.e. we make choices to act on the basis of a maxim which has universal validity for every rational being, and so we cannot use others merely as a means to an end) or on the consequences of the act or decision (i.e. we make choices to act which potentially offer the greatest net benefit for the greatest number of people) or we seek to proportionately balance duties or rules with empirical consequences in order to find the virtuous mean in the situation at hand (Walker and Lovat 2018: 45).

If we take the example of the death penalty, Kantian ethicists will focus on the act itself (killing is wrong, because every human being has human dignity), while utilitarian ethicists will be concerned about the consequences of the act (they may argue that death penalty is not effective punishment: the criminal may not be afraid of dying but more afraid of the perspective of spending the whole life in prison or that it causes more killing); virtue ethicists will most likely argue that what matters is how the act is related to the emotions related to the act (as death penalty is a sort of revenge and is related to anger and fear, it is not moral).

When representatives of different theories speak about an action as 'morally good' they may refer to various properties: the character of an actor, the motive, the consequence of an action or the action itself. The different focus of attention is also reflected in the language used in various moral theories: right or wrong, good or bad, 
virtuous or vicious. Can we classify these as merely verbal disagreements? I do not think so. These disagreements are not caused by a communicative error, where the representatives of different ethical theories simply talk past each other, as is typical of merely verbal disagreements. Different theories prioritize different aspects of moral action: whereas consequentialists concentrate on consequences, deontological theories put stress on the moral worth of an action, and virtue ethicists evaluate the character of the actor. Thus, it is not a merely verbal disagreement that we see here but deep conceptual disagreement, as it proceeds from a clash in underlying principles.

\section{Conclusions}

We have seen that some moral disagreements are deep conceptual disagreements which, similarly to disagreements in logic, are not resolvable, for the resolution of the disagreement requires the disputants to adopt perspectives that are conceptually unavailable to them. I suggested four possible sources of moral disagreements: firstly, we may have different identities and concepts of good life, secondly, we have incommensurable fundamental values; thirdly, we may have different motivating reasons for moral actions, and fourthly, we may have different concepts of morality.

People differ not only in how they decide to act when confronted with value choices, but also in how they justify their choices. Sometimes people choose the same option but provide different justificatory reasons for it. Some refer continuously to considerations of utility or concern about others' welfare, while others say that it is important to do the right thing. Some are oriented to good relationships with other people, and others work on consensus-building; still others find it important to exemplify certain virtues. The justifications of their choices also reveal their loyalties and worldview.

Why is it important to know that some moral disagreements are deep conceptual disagreements? Firstly, this will show that the persistence of disagreements over moral issues does not prove that objectivism and realism are wrong as in ethics there may be no unique answer to moral questions. Secondly, this will have practical consequences. If it is not possible to resolve moral disagreements by rational argumentation, we should understand what causes our disagreements, what we have in common and on what basis we can build consensus or make compromises.

\section{Acknowledgements}

This paper is an outcome of the research project "Disagreements: A Philosophical Analysis" (IUT20-5), funded by the Estonian Ministry of Education and Research and supported by the Centre of Excellence in Estonian Studies (European Union, European Regional Development Fund). The article has been written at the time of holding the Kone Fellowship at the Helsinki Collegium for Advanced Studies at the University of Helsinki whose support I gratefully acknowledge. I would like to thank 
Tiina Kirss for her careful editing and help with English expression, Heidy Meriste, Bruno Mölder, Kristi Lõuk, Mari-Liisa Parder for their valuable suggestions, and Laura Lilles-Heinsar for help with references.

Address:

Margit Sutrop

Department of Philosophy

University of Tartu

Jakobi 2

50090 Tartu, Estonia

E-mail: Margit.Sutrop@ut.ee

Tel.: +3725207183

\section{References}

Adams, David (2005) “Knowing when disagreements are deep”. Informal Logic 25, 1, 65-77.

Ahola, Salla (2017) "Why (not) disagree? Human values and the readiness to question experts' views". Public Understanding of Science 26, 3, 339-354.

Airaksinen, Timo (2016) "Narratives of desire". In Timo Airaksinen and Wojciech W. Gasparski, eds. Desire: the concept and its practical context, 3-58. New Brunswick: Transaction Publisher.

Archard, David (2012) "Moral compromise". Philosophy 87, 341, 403-420.

Bartels, D. (2008) "Principled moral sentiment and the flexibility of moral judgement and decision making". Cognition 108, 381-417.

Benn, Stanley (1988) A theory of freedom. Cambridge: Cambridge University Press.

Berlin, Isaiah (1947/2013) “The pursuit of the ideal". In Henry Hardy, ed. The crooked timber of humanity. Princeton and Oxford: Princeton University Press.

Berlin, Isaiah (1958/2002) “Two concepts of liberty”. In Henry Hardy, ed. Liberty. Oxford, New York: Oxford University Press.

Blackburn, Simon (1998) Ruling passions. a theory of practical reasoning. Oxford: Oxford University Press.

Blackburn, Simon (1999) "Is objective moral justification possible on a quasi-realist foundation?". Inquiry 42, 2, 213-227.

Bond, E. J. (2001) "Value, concept of". In Lawrence C. Becker and Charlotte B. Becker, eds. Encyclopedia of Philosophy. 2nd ed. Vol. 3, 1745-1749. New York, London: Routledge.

Brink, David (1989) Moral realism and the foundations of ethics. Cambridge: Cambridge University Press.

Brunning, Luke (2019) "The avoidance approach to plural value". Theoria 160, 66, 3, 53-70.

Ceva, Emanuela (2016) Interactive justice: a proceduralist approach to value conflict in politics. New York: Routledge.

Chang, Ruth (1997) "Introduction". In R. Chang, ed. Incommensurability, incomparability, and practical reason, 1-34. Cambridge, Massachusetts: Harvard University Press.

Decker, Jason and Daniel Groll (2013) "On the (in)significance of moral disagreement for moral knowledge”. In R. Shafer-Landau, ed. Oxford studies in metaethics. Vol. 4. Oxford: Oxford University Press.

Duran, Claudio (2006) "Levels of depth in deep disagreement". OSSA Conference Archive 11: 1-8.

Fogelin, Robert J. (1985) “The logic of deep disagreements". Informal Logic 7, 1, 3-11. 
Frances, Bryan (2014) Disagreement. Cambridge: Polity.

Frances, Bryan and Jonathan Matheson (2018) "Disagreement". In Edward N. Zalta, ed. The Stanford encyclopedia of philosophy. Available online at $<$ https://plato.stanford.edu/archives/win2019/ entries/disagreement/>. Accessed on May 1, 2020.

Gibbard, Allan (2003) Thinking how to live. Cambridge, Mass.: Harvard University Press.

Gordijn, Bert (2001) "Regulating moral dissent in an open society: the Dutch experience with pragmatic tolerance". Journal of Medicine and Philosophy 26, 3, 225-244.

Gowans, Christopher W. (1987) "Introduction: the debate on moral dilemmas". In C. W. Gowans, ed. Moral dilemmas, 3-33. New York, Oxford: Oxford University Press.

Gowans, Christopher W. (2000) Moral disagreements: classic and contemporary readings. London: Routledge.

Griffin, James (1986) Well-being. Oxford: Oxford University Press.

Haidt, Jonathan (2012) The righteous mind: why good people are divided by politics and religion. New York: Pantheon Books.

Hanrick, Fieke and Daniel Druckman (2017) "Do negotiation interventions matter? Resolving conflicting interests and values". Journal of Conflict Resolution 61, 1, 29-55.

Harman, Gilbert (1975) "Moral relativism defended". Philosophical Review 84, 3-22.

Harman, Gilbert (2000) Explaining values and other essays in moral philosophy. New York: Oxford University Press.

Hare, Richard Mervin (1963) Freedom and reason. Oxford: Oxford University Press.

Inglehart, R., C. Haerpfer, A. Moreno, C. Welzel, K. Kizilova, J. Diez-Medrano, M. Lagos, P. Norris, E. Ponarin, B. Puranen et al., eds. (2014) World values survey: round six - country-pooled datafile. Madrid: JD Systems Institute. Available online at <www.worldvaluessurvey.org/ WVSDocumentationWV6.jsp>. Accessed on May 1, 2020.

Inglehart, Ronald and Christian Welzel (2005) Modernization, cultural change and democracy. New York, Cambridge: Cambridge University Press.

Kekes, John (1993) The morality of pluralism. Princeton, New Jersey: Princeton University Press.

MacIntyre, Alasdair (1984) After virtue: a study in moral theory. 2nd ed. London: Duckworth.

Mackie, John (1977). Ethics: inventing right and wrong. New York: Penguin.

Marino, Patricia (2015) Moral reasoning in a pluralistic world. Montreal and Kingston: McGillQueen's University Press.

Marino, Patricia (2017) "Value pluralism, moral diversity, moral reasoning, and the foundation of bioethics". Ethics, Medicine and Public Health 3, 477-485.

Mason, Andrew (2013) Explaining political disagreement. Cambridge: Cambridge University Press.

Mason, Elinor (2018) "Value pluralism". In Edward N. Zalta, ed. The Stanford encyclopedia of philosophy. Available online at $<$ https://plato.stanford.edu/archives/spr2018/entries/valuepluralism/>. Accessed on May 1, 2020.

McGrath, Sarah (2007) "Moral disagreement and moral expertise". In Russ Shafer-Landau, ed. Oxford studies in metaethics. Vol. 4. Oxford: Oxford University Press.

McNaughton, David (1988) The moral vision. Oxford: Basil Blackwell.

McNaughton, David and Piers Rawling (1992) "Honoring and promoting values". Ethics 102, 4, 835-843.

Nagel, Thomas (1979) "The fragmentation of value". In his Mortal questions. Ch. 9, 128-141. Cambridge: Cambridge University Press.

Nussbaum, Martha (1986) The fragility of goodness: luck and ethics in greek tragedy. Cambridge: Cambridge University Press. 
Nussbaum, Martha (2001) Upheavals of thought: the intelligence of emotions. Cambridge: Cambridge University Press.

Orsi, Francesco (2015) Value theory. London: Bloomsbury.

Pettit, Philip (1989) "Consequentialism and respect for persons". Ethics 100, 1, 116-126.

Ranalli, Chris (2018) “What is deep disagreement?”. Topoi. doi: https://doi.org/10.1007/s11245-018-9600-2

Raz, Joseph (1986) The morality of freedom. Oxford: Oxford University Press.

Schroeder, Mark (2016) "Value theory". In Edward N. Zalta, ed. The Stanford encyclopedia of philosophy. Available online at $<$ https://plato.stanford.edu/archives/fall2016/entries/valuetheory/>. Accessed on May 1, 2020.

Seung T. K. and Daniel Bonevac (1992) "Plural values and indeterminate rankings". Ethics 102, 4, 799-813.

Shafer-Landau, Russ (2005) Moral realism: a defence. Oxford: Clarendon Press.

Smith, Michael (1994) The moral problem. Oxford: Blackwell.

Spang, Friderike Marta Gabriela (2017) Dealing with disagreement: towards a conception of feasible compromise. Electronic Thesis and Dissertation Repository. 4919. Available online at $<\mathrm{https}$ :/ ir.lib.uwo.ca/etd/4919>. Accessed on May 1, 2020.

Stevenson, Charles Leslie (1963) Facts and values: studies in ethical analysis. New Haven: Yale University Press.

Stocker, Michael (1990) Plural and conflicting values. Oxford: Clarendon Press.

Sutrop, Margit (2015) "Can values be taught? A myth of value-free education". Trames 19, 2, 189-202.

Sutrop, Margit (2016) "What role do emotions play in moral disagreements?". In Timo Airaksinen and Wojciech W. Gasparski, eds. Desire: the concept and its practical context, 183-199. New Brunswick: Transaction Publisher.

Sutrop, Margit and Kadri Simm (2020) "Developing guidelines for the distribution of scarce medical resources during the COVID-19 pandemic: the Estonian case". Trames 24, 2, 251-268.

Viganò, Eleanora and Edoardo Lombardi Vallauri (2020) "Moral and vocational dilemmas meet the common currency hypothesis: a contribution to value commensurability". Review of Philosophy and Psychology 11, 83-102.

Walker, Paul and Terence Lovat (2018) "In a world characterized by moral pluralism, is dialogic consensus a way to establish moral truth?". Review of Contemporary Philosophy 17, 43-55. doi:10.22381/RCP1720184.

Williams, Bernard (1965/1973a) "Ethical consistency". In his Problems of the self, 166-186. Cambridge: Cambridge University Press.

Williams, Bernard (1973b) "Morality and the emotions". In his Problems of the self, 207-229. Cambridge: Cambridge University Press.

Williams, Bernard (1981) Moral luck. Philosophical papers 1973-1980. Cambridge: Cambridge University Press.

Williams, Bernard (1985) Ethics and the limits of philosophy. Cambridge, Mass.: Harvard University Press.

Wong, David B. (1992) “Coping with moral conflict and ambiguity”. Ethics 102, 4, 763-784.

Wong, David B. (1995) "Pluralistic relativism”. Midwest Studies in Philosophy 20, 378-399.

Wong, David B. (2006) "Ethical relativism (addendum)”. In Donald M. Borchert, ed. Encyclopedia of philosophy, 372-374. 2nd ed. Detroit: Thomson Gale.

Zuolo, Frederico and Giulia Bistagnino (2018) "Disagreement, peerhood, and compromise". Social Theory and Practice 44, 4, 593-618. 